\title{
Patients direct costs to undergo TB diagnosis
}

\author{
Rachel M. Anderson de Cuevas ${ }^{1}$, Lovett Lawson ${ }^{2,3}$, Najla Al-Sonboli ${ }^{4}$, Nasher Al-Aghbari ${ }^{5}$, Isabel Arbide ${ }^{6}$, \\ Jeevan B. Sherchand ${ }^{7}$, Emenyonu E. Nnamdi ${ }^{2}$, Abraham Aseffa ${ }^{8}$, Mohammed A. Yassin ${ }^{1,9}$, \\ Saddiq T. Abdurrahman ${ }^{10}$, Joshua Obasanya ${ }^{11}$, Oladimeji Olanrewaju ${ }^{2}$, Daniel Datiko ${ }^{12}$, Sally J. Theobald ${ }^{1}$, \\ Andrew Ramsay ${ }^{13}$, S. Bertel Squire ${ }^{1}$ and Luis E. Cuevas ${ }^{1 *}$ (D)
}

\begin{abstract}
Background: A major impediment to the treatment of $\mathrm{TB}$ is a diagnostic process that requires multiple visits. Descriptions of patient costs associated with diagnosis use different protocols and are not comparable.

Methods: We aimed to describe the direct costs incurred by adults attending TB diagnostic centres in four countries and factors associated with expenditure for diagnosis. Surveys of 2225 adults attending smear-microscopy centres in Nigeria, Nepal, Ethiopia and Yemen. Adults $>18$ years with cough $>2$ weeks were enrolled prospectively. Direct costs were quantified using structured questionnaires. Patients with costs $>75^{\text {th }}$ quartile were considered to have high expenditure (cases) and compared with patients with costs $<75^{\text {th }}$ quartile to identify factors associated with high expenditure.

Results: The most significant expenses were due to clinic fees and transport. Most participants attended the centres with companions. High expenditure was associated with attending with company, residing in rural areas/other towns and illiteracy.

Conclusions: The costs incurred by patients are substantial and share common patterns across countries. Removing user fees, transparent charging policies and reimbursing clinic expenses would reduce the poverty-inducing effects of direct diagnostic costs. In locations with limited resources, support could be prioritised for those most at risk of high expenditure; those who are illiterate, attend the service with company and rural residents.
\end{abstract}

Keywords: Tuberculosis, Costs, Access to healthcare, Ethiopia, Nepal, Nigeria, Yemen

\section{Multilingual abstract}

Please see Additional file 1 for translations of the abstract into the six official working languages of the United Nations.

\section{Background}

TB is a disease of poverty mostly affecting populations with limited resources and restricted access to health services in low and middle income countries (LMICs). For this reason the WHO has included a specific financial risk protection target in the new End TB Strategy

\footnotetext{
*Correspondence: Luis.Cuevas@lstmed.ac.uk

'Liverpool School of Tropical Medicine, Pembroke Place, Liverpool L3 5QA, UK

Full list of author information is available at the end of the article
}

[1], that no TB affected household should experience catastrophic costs due to TB [2].

Access to services is also a major problem. Of the 9.5 million incident cases estimated by the WHO in 2013, only 6 million were reported and the rest were either not diagnosed, or diagnosed but not reported to national TB programmes (NTPs) [3]. Over 77 million smear investigations are conducted every year in the top twenty high burden countries, most of these in poor people [4]. Although drugs for first-line treatment for TB are provided for free by most NTPs [5], the financial costs incurred by the patient and their family for diagnosis remain significant $[6,7]$ and further costs may include hospitalisation, treatment of side effects, nutrition and others.

The onset of disease often exacerbates poverty, as the patient enters a lengthy period of expenditure on 
healthcare and productivity losses [8]. Direct costs start with the patient undertaking consultations to reach a diagnosis; yet these costs had been overlooked by policymakers until recently [1,9]. Although TB diagnostics tests are free of charge in most countries, public health services often charge patients for their initial clinical consultation, non-specific medications and other diagnostic tests, such as $\mathrm{x}$-rays $[10,11]$. Patients must also meet the cost of displacement from home, including domestic responsibilities, subsistence and loss of earnings. Costs are augmented by the need for patients to spend several days near the health facility to complete the tests and meet health staff for clinical management decisions [12, 13].

The cost of diagnosis is not uniform for all patients and some have higher expenses than others. Identifying individuals at risk of unusually high expenditure would be of value to health programmes and policy makers to inform the development of interventions to support patients with limited resources and high expenditure. Few studies have isolated the patients' direct and indirect costs of attending NTP health facilities for diagnosis and even fewer have compared expense patterns across countries.

This study examined the direct financial costs incurred by adults attending smear-microscopy based TB diagnostic centres in Ethiopia, Nepal, Nigeria and Yemen and the risk factors for high expenditure for diagnosis. This information was used to identify the population groups that are more likely to experience higher costs to undergo the TB diagnostic process.

\section{Methods}

Ethical approvals for the study were obtained from the research ethics committees of the Liverpool School of Tropical Medicine, the Institutional Review Boards of the World Health Organisation and all the participating institutions in Ethiopia, Nepal, Nigeria, and Yemen. All participants gave written informed consent.

The study comprised four cross-sectional surveys using the same study protocol among patients undergoing routine smear microscopy in Ethiopia, Nepal, Nigeria and Yemen [14]. These countries were selected because the team was conducting a multi-country study to optimise the use of smear microscopy and represented high burden countries across three World Health Organization regions [14]. Adults over 18 years with chronic cough of more than 2 weeks duration attending selected health facilities were invited to participate. Participants were selected using systematic random sampling, with a maximum of 10 patients interviewed each day. In Ethiopia, participants were enrolled in Bushullo Major Health Centre, a not-for-profit mission hospital located in the outskirts of Hawassa; capital of the Southern Region; in Nepal, patients were enrolled at
Tribhuvan University Teaching Hospital, a governmental referral hospital in Kathmandu; in Abuja Nigeria, patients were enrolled in Wuse District Hospital, a government general hospital and in Yemen, patients were selected from the National Tuberculosis Institute (NTI), a government referral centre and the main centre for the diagnosis of TB in Sana'a. These centres were selected as they were integral to the NTP services and large numbers of patients received a diagnosis of TB. The approximate number of patients routinely screened for TB in each centre was 260, 1000, 250 and 780 per month in Ethiopia, Nepal, Nigeria and Yemen, respectively. Individuals attending the centres self-referred or were referred by government, private or informal health care providers. A minimum of 500 patients were expected to be recruited from each study site to obtain a representative sample of patients attending the centre and to have at least $80 \%$ power to identify risk factors with an Odds Ratio $>1.5$.

Participants were interviewed using standard questionnaires to obtain demographic and clinical information, to establish whether they had travelled with company and the direct costs associated with attending the centre. The questionnaire was structured and administered face to face. Variables were defined using quantitative scales. The questionnaire had been developed over several studies preceding the study and developed jointly by all co-authors to allow for local sensitivities and pooling of expertise. Questionnaires were administered by local research staff specifically trained and employed for the study, using the local languages and took about 30 min per patient. Participants who were illiterate were supported by local staff to clarify the questions and to estimate costs. Very few patients refused to participate, and $>95 \%$ of patients consented on first approach. Patients who refused often did because they were in a hurry or (in some settings) they preferred to be interviewed with a partner who was not present at the time of the interview. A pilot study was run in all countries before the main surveys and questions were adjusted as needed. Direct costs were defined as medical (clinic fees or registration costs, cost of investigation or consultation, diagnostic tests and medication) and the costs of transportation, food and accommodation for patient and companion/s). Direct costs also included travel, overnight stays, expenditure needed to attend the second day of diagnosis and others related to the current visit. Indirect costs, defined as the loss of income for patient and household due to lost work days, incapacity to work or forced changed of occupation and substitution costs (the cost of replacing the patient in their duties) and costs for previous health service encounters were not measured.

Data were entered in a database using Epi-Info. The participants' characteristics by country were described using summary statistics. Proportions were compared using chi square tests and means were compared using 
parametric and non-parametric tests for normal and skewed data, respectively. Costs were described using quartiles and expressed as the median and $25-75^{\text {th }}$ interquartile range (25-75\% IQR). Costs were calculated by adding the figures in the local currencies for each day of attendance and converting the day's total to US dollars using the exchange rate at the beginning of the study. Median expenditures were described stratified by selected patient characteristics (e.g. rural/urban residency) and compared using non parametric tests. Patients with costs $>75^{\text {th }}$ quartile were considered to have high expenditure (cases) and were compared with patients with costs $<75^{\text {th }}$ quartile, to identify factors associated with high expenditure. Odds Ratios (OR) with $95 \%$ confidence intervals $(95 \% \mathrm{CI})$ were calculated and variables with $\mathrm{p}$ values $<0.2$ were entered into backward and forward logistic regressions to identify factors independently associated with high expenditure (Adjusted OR, AOR).

\section{Results and discussion}

A total of 2225 patients were enrolled, of whom 504 were enrolled in Ethiopia, 619 in Nepal, 502 in Nigeria and 600 in Yemen. Patients had a mean (SD) age of 39 (17) years and were more likely to be male than female in all countries except Nigeria (Table 1). The majority of patients $(67 \%)$ were married or had partners; $27 \%$ were single and few were widowed (5\%) or divorced/ separated (2\%). Between $10 \%$ (Nepal) and $47 \%$ (Yemen) of patients resided in rural areas and the majority of urban patients resided in the town where the study health centre was located; except in Nepal, where almost half of the patients from urban areas came from other cities. The mean (SD) number of residents per household was 6.1 (4), ranging from 4.1 (3) in Nigeria to 8.6 (5) in Yemen.

The majority of patients were accompanied by another person in all countries except Nigeria, as shown in Table 2. The accompanying person was a relative other than the spouse in $77 \%$ of patients, the spouse in $15 \%$ and $8 \%$ were accompanied by other people. Few patients walked to the clinics and the most common transport methods were buses in Nigeria, Nepal and Ethiopia and cars or taxis in Yemen. Horse cart and motorbike travel were also common in Ethiopia (26\%) and Nepal (17\%), respectively. The median (25-75\% IQR) travel time to the health centre was $40(20-66)$ minutes. Travel time was shortest in Nepal $(25 ; 15-30 \mathrm{~min})$ and longest in Yemen $(60,30-150 \mathrm{~min})$. The majority of patients intended to spend the night at home the first day of consultation (66\%), except in Nepal where $46 \%$ planned to stay with a relative. Very few patients paid for hotel accommodation. Transport patterns for the second day of consultation where similar, except in Yemen where patients realised that there was a low cost taxi service and a lower number decided to travel by private car the second day (data not shown).

Table 1 Patients' demographic characteristics by country

\begin{tabular}{|c|c|c|c|c|c|c|}
\hline \multicolumn{2}{|l|}{ Variables $^{a}$} & \multirow{2}{*}{$\begin{array}{l}\text { Ethiopia } N=504 \\
33.2(14.5)\end{array}$} & \multirow{2}{*}{$\begin{array}{l}\text { Nepal } N=619 \\
43.8(17.8)\end{array}$} & \multirow{2}{*}{$\begin{array}{l}\text { Nigeria } N=502 \\
34.4(11)\end{array}$} & \multirow{2}{*}{$\begin{array}{l}\text { Yemen } N=600 \\
41.8(18.3)\end{array}$} & \multirow{2}{*}{$\begin{array}{l}\text { All } N=2225 \\
38.7(16.6)\end{array}$} \\
\hline Age & (Mean, \pm SD) & & & & & \\
\hline Gender & male: female (\% male) & 279: 225 (55.4) & 395: $224(63.8)$ & 241: $258(48.0)$ & 329: 271 (54.8) & 1244: 978 (55.9) \\
\hline \multirow[t]{4}{*}{ Marital status } & Single & $176(34.9)$ & $107(17.3)$ & $183(36.5)$ & $124(20.7)$ & $590(26.5)$ \\
\hline & With partner/married & $302(59.9)$ & $507(81.9)$ & $259(51.6)$ & $426(71)$ & $1494(67.1)$ \\
\hline & Divorced/separated & $12(2.4)$ & $0(0)$ & $13(2.6)$ & $10(1.7)$ & $35(1.6)$ \\
\hline & Widowed & $14(2.8)$ & $5(0.8)$ & $44(8.8)$ & $40(6.7)$ & $103(4.6)$ \\
\hline \multirow[t]{3}{*}{ Residence } & Rural & $182(36.1)$ & $63(10.2)$ & $82(16.3)$ & $279(46.5)$ & $606(27.2)$ \\
\hline & Same town & $216(42.9)$ & $284(45.9)$ & $410(81.7)$ & $268(44.7)$ & $1178(52.9)$ \\
\hline & Other town & $106(21)$ & $272(43.9)$ & $7(1.4)$ & $53(8.8)$ & $438(19.7)$ \\
\hline \multicolumn{2}{|c|}{ Literate: Illiterate (\% literate) } & 247: 257 (49) & 475: $137(76.7)$ & 439: 57 (87.5) & 264: $336(44.0)$ & 1425: 787 (64) \\
\hline \multirow[t]{6}{*}{ Education } & Nil & $257(51)$ & $197(31.8)$ & $41(8.2)$ & $311(51.8)$ & $806(36.2)$ \\
\hline & Primary incomplete & $117(23.2)$ & $37(6)$ & $42(8.4)$ & $126(21)$ & $322(14.5)$ \\
\hline & Primary complete & $43(8.5)$ & $105(17)$ & $63(12.5)$ & $56(9.3)$ & $267(12)$ \\
\hline & Secondary & $62(12.3)$ & $127(20.5)$ & $220(43.8)$ & $61(10.2)$ & $470(21.1)$ \\
\hline & Tertiary & $24(4.8)$ & $153(24.7)$ & $133(26.5)$ & $46(7.7)$ & $356(16)$ \\
\hline & Missing & $1(0.2)$ & $0(0)$ & $3(0.6)$ & $0(0)$ & $4(0.2)$ \\
\hline \multicolumn{2}{|c|}{ Working: not working (\% working) } & 235: $269(46.6)$ & 202: 417 (32.6) & 368: $131(73.3)$ & 164: $436(27.3)$ & 969: 1253 (43.6) \\
\hline \multicolumn{2}{|c|}{ Mean (SD) residents in household } & $5.7(2.9)$ & $5.5(3)$ & $4.1(3)$ & $8.6(5)$ & $6.1(4)$ \\
\hline
\end{tabular}

${ }^{\mathrm{a}}$ Data represent frequency (\%), unless otherwise specified. Sex, residency, marital and work status were missing for 3 patients and literacy for 13 patients 
Table 2 Characteristics of patients attending the clinics

\begin{tabular}{|c|c|c|c|c|c|c|}
\hline \multicolumn{2}{|l|}{ Variables $^{a}$} & Ethiopia $N=504$ & Nepal N=619 & Nigeria $N=502$ & Yemen $N=600$ & All $N=2225$ \\
\hline \multicolumn{2}{|c|}{ Alone: With company (\% accompanied) } & 129:373 (74) & 181:435 (70.3) & $320: 177(35.3)$ & 91:509 (84.8) & 721:1494 (67.1) \\
\hline \multirow[t]{5}{*}{ Accompanying person } & Spouse & $61(16.4)$ & $62(14.3)$ & $50(28.2)$ & $51(10)$ & $224(15)$ \\
\hline & Other relative & $276(74)$ & $336(77.2)$ & $94(53.1)$ & $439(86.2)$ & $1145(76.6)$ \\
\hline & Friend & $13(3.5)$ & $17(3.9)$ & $19(10.7)$ & $17(3.3)$ & $66(4.4)$ \\
\hline & Neighbour & $7(1.9)$ & $10(2.3)$ & $1(0.6)$ & $0(0)$ & $18(1.2)$ \\
\hline & Other & $16(4.3)$ & $9(2.1)$ & $13(7.3)$ & $2(0.4)$ & $40(2.7)$ \\
\hline \multicolumn{2}{|c|}{ Travel time, median (25-75 IQR), min } & $45(27-120)$ & $25(15-30)$ & $45(30-60)$ & $60(30-150)$ & $40(20-66)$ \\
\hline \multirow[t]{9}{*}{ Transport day 1} & Walking & $67(13.3)$ & $92(14.9)$ & $12(2.4)$ & $12(2)$ & $183(8.2)$ \\
\hline & Carried & $6(1.2)$ & $0(0)$ & $2(0.4)$ & $0(0)$ & $8(0.4)$ \\
\hline & Bicycle & $14(2.8)$ & $7(1.1)$ & $0(0)$ & $0(0)$ & $21(0.9)$ \\
\hline & Cart/horse & $129(25.6)$ & $5(0.8)$ & $0(0)$ & $4(0.7)$ & $138(6.2)$ \\
\hline & Motorbike & $1(0.2)$ & $104(16.8)$ & $2(0.4)$ & $3(0.5)$ & $110(4.9)$ \\
\hline & Bus & $148(29.4)$ & $303(48.9)$ & $303(60.4)$ & $127(21.2)$ & 881 (39.6) \\
\hline & Car & $33(6.5)$ & $14(2.3)$ & $76(15.1)$ & 203 (33.8) & $326(14.7)$ \\
\hline & Taxi & $103(20.4)$ & $83(13.4)$ & $101(20.1)$ & $250(41.7)$ & $537(24.1)$ \\
\hline & Other & $1(0.2)$ & $8(1.3)$ & $1(0.2)$ & $1(0.2)$ & $11(0.5)$ \\
\hline \multirow[t]{8}{*}{ Transport day 2} & Walking & $118(23.4)$ & $104(16.8)$ & $13(2.6)$ & $12(2)$ & 247 (11.1) \\
\hline & Carried & $3(0.6)$ & $2(0.3)$ & $2(0.4)$ & $1(0.2)$ & $8(0.4)$ \\
\hline & Bicycle & $13(2.6)$ & $9(1.5)$ & $0(0)$ & $0(0)$ & $22(1)$ \\
\hline & Cart/horse & $181(35.9)$ & $5(0.8)$ & $0(0)$ & $5(0.8)$ & $191(8.6)$ \\
\hline & Motorbike & $1(0.2)$ & $104(16.8)$ & $1(0.2)$ & $3(0.5)$ & 109 (4.9) \\
\hline & Bus & $44(8.7)$ & $298(48.1)$ & 309 (61.6) & $143(23.8)$ & $794(35.7)$ \\
\hline & Taxi & $108(21.4)$ & 72 (11.6) & $73(14.5)$ & $327(54.5)$ & $580(26.1)$ \\
\hline & Other & $5(1)$ & $9(1.5)$ & $38(7.6)$ & $0(0)$ & $52(2.3)$ \\
\hline \multirow[t]{6}{*}{ Accommodation } & Home & $358(71)$ & $267(43.1)$ & 437 (87.1) & 407 (67.8) & $1469(66)$ \\
\hline & Relative & 60 (11.9) & $282(45.6)$ & $5(1)$ & $123(20.5)$ & $470(21.1)$ \\
\hline & Hotel & $66(13.1)$ & $40(6.5)$ & $0(0)$ & $68(11.3)$ & $174(7.8)$ \\
\hline & Street & $2(0.4)$ & $0(0)$ & $1(0.2)$ & $0(0)$ & $3(0.1)$ \\
\hline & Shift & $1(0.2)$ & $6(1.0)$ & $0(0)$ & $0(0)$ & $7(0.3)$ \\
\hline & Hospital & $15(3.0)$ & $20(3.2)$ & $54(10.8)$ & $2(0.3)$ & $91(4.1)$ \\
\hline
\end{tabular}

a Data are frequency (\%), unless specified. Patients' data missing for whether they attended with company (i10,) person accompanying (1), accommodation (11 and transport (18). Min = minutes. $\mathrm{P}$ values for all comparisons between countries $<0.05$, except for accompanying person being the spouse $(p=0.26)$ and Being carried $(p=0.69)$

\section{Costs of attending the clinic}

Costs associated with the two-day clinic attendance are summarised in Table 3. Second day expenses were similar to first day expenses. The median costs were higher in Yemen (\$11.89) and Nepal (\$8.22) and lower in Nigeria (\$5) and Ethiopia (\$1.47). The most significant expenses were due to the clinic costs (except Nigeria) and transport. Miscellaneous expenses were frequently reported in Nepal (83\% of patients) and were rare in Yemen (12\%), Nigeria (3\%) and Ethiopia (0 \%). Although rare in Yemen, these expenses were significant. Very few patients paid for overnight accommodation in all countries and the median (25\% \& $75 \%$ IQR) expenditure was 0 in all countries.

The costs of attending the clinic stratified by the patients' characteristics are described in Table 4. Older patients, those attending the clinic with company, residing in rural areas or coming from other towns and patients not working, had higher median costs than younger patients, those attending alone, residing in the same town or working. Farmers, students and housewives had higher median costs than patients with other occupations. Patients with a confirmed TB diagnosis (smear and culture positive) had higher costs than patients without laboratory 
Table 3 Median and IQR costs incurred for attending the clinic

\begin{tabular}{|c|c|c|c|c|}
\hline Variable $^{a}$ & $\begin{array}{l}\text { Ethiopia ETB } \\
N=504\end{array}$ & $\begin{array}{l}\text { Nepal NPR } \\
N=619\end{array}$ & $\begin{array}{l}\text { Nigeria NGN } \\
N=502\end{array}$ & $\begin{array}{l}\text { Yemen YER } \\
N=600\end{array}$ \\
\hline Proportion reporting miscellaneous expenses, $\mathrm{N}(\%)^{b}$ & $0(0)$ & $509(82.6 \%)$ & $13(2.6 \%)$ & $73(12.2 \%)$ \\
\hline Clinic costs & $8(5 ; 8)$ & $300(300 ; 300)$ & $0(0 ; 150)$ & $450(250 ; 450)$ \\
\hline Transport & $16(4 ; 36)$ & $48(0 ; 100)$ & $400(200 ; 600)$ & $2000(800 ; 3400)$ \\
\hline Food & $0(0 ; 12)$ & $0(0 ; 0)$ & $200(0 ; 400)$ & $0(0 ; 400)$ \\
\hline Overnight accommodation & $0(0 ; 0)$ & $0(0 ; 0)$ & $0(0 ; 0)$ & $0(0 ; 0)$ \\
\hline Miscellaneous expenditure & $0(0 ; 0)$ & $300(200 ; 300)$ & $500(200 ; 1000)$ & $1000(500 ; 2000)$ \\
\hline Total & ETB $24(11 ; 58)$ & NPR $604(500 ; 900)$ & NGN $760(420 ; 1400)$ & YER $2550(1400 ; 4850$ \\
\hline Total (US \$) & $\$ 1.47$ & $\$ 8.22$ & $\$ 5.00$ & $\$ 11.89$ \\
\hline Proportion of poor/general population $(\mathrm{H})$ using $\mathrm{MPI}^{\mathrm{c}}$ & 0.900 & 0.647 & 0.635 & 0.525 \\
\hline Proportion of poor/general population $<\$ 1.25 /$ day $^{\text {d }}$ & 0.390 & 0.551 & 0.644 & 0.175 \\
\hline Conversion rate to USD & $1=0.061$ & $1=0.013$ & $1=0.007$ & $1=0.005$ \\
\hline
\end{tabular}

${ }^{a}$ Values are medians and 25-75\% interquartile ranges (IQR) and given in the local currency, unless specified otherwise

${ }^{b}$ Data missing for 10 patients ( 2 in Ethiopia, 3 in Nepal and 5 in Nigeria)

'Figures derived from the Multidimensional Poverty Index [34]

${ }^{\mathrm{d}}$ Proportion of people living on $<\$ 1.25 /$ day, World Development Indicators, World Bank 2009

confirmation and expenses were similar among males and females.

A total of 538 cases with expenditure $>75^{\text {th }}$ centile (high expenditure) and 1679 patients with expenditure $<75^{\text {th }}$ centile (controls) were analysed. Factors associated with high patient expenditure at the univariate and multivariate analysis are shown in Table 5.

Although there were considerable differences between countries, residing in a rural area/other town (OR (95 \% CI) 23.6 (10.2-55); 1.5 (1.0-2.2) and 6.9 (4.211.3), respectively), having low education (2.5 (1.3-4.8), 1.4 $(1.0-2.1)$ and $1.9(1.1-3.3)$, respectively) and attending with company $(19.7(6.1,63), 1.5(1.0-2.2)$ and 3.4 (1.7-7.0), respectively) were risk factors for high expenditure in Ethiopia, Nepal and Yemen at the univariate level. Of these, illiteracy (OR (95\% CI) $2.4(1.4-4.3)$ and being accompanied (OR (95 \% CI) 2.7 (1.8-4.2) were also statistically significant in Nigeria. Variables independently associated with high expenditure in the multivariate analysis, were attending the clinic with company (Ethiopia (AOR 7.5 (2.3-25.2), Yemen (AOR 3.1 (1.5-6.5) and Nigeria (AOR $2.5(1.6-3.9)$ ), residing in rural areas and other towns (Ethiopia (AOR $15.3(6.5-36.0)$ and Yemen 6.7 (4.1-11.0)), illiteracy (Nigeria (AOR $1.9(1.0-3.4)$ and Nepal (AOR 2.5 (1.5-4.0)) and males with bacteriologically confirmed TB (Nepal, AOR 2.0 (1.3-3.2)).

Many illnesses are associated with poverty and individuals often consider their financial position before attending health facilities. TB is no exception. As a disease of poverty, TB is associated with many patients never attending health services, attending late, or dropping out after initiation of the diagnostic process $[10,15,16]$. As TB diagnostic services are not available in all health facilities, patients often express concerns about multiple consultations, service fees, travel expenses and lost time and opportunity costs [17]. This analysis confirms that the direct costs sustained by patients undergoing a diagnosis of TB across multiple settings are substantial. A large component of these are associated with clinic costs, transport and patients attending the services with company. According to the Multidimensional Poverty Index, of the four countries Yemen, ranked as the least poor at the time of the study, followed by Nigeria, Nepal and Ethiopia [2]. Although it is difficult to compare costs and expenditure directly between countries, as living costs and income were very different across study settings, our findings identified remarkable similarities.

Clinic user fees comprised a common and significant cost. These fees are known to have a negative impact on general health service utilisation and this is likely to be more prominent in $\mathrm{TB}$ patients with limited financial resilience [18]. Clinic costs for attending TB clinics in the study comprised consultation fees, smear microscopy, X-rays and blood tests to screen for other diseases [19]. Furthermore, although not captured in the study, bacteriologically negative cases may undergo further consultation and testing, pay for further visits and have higher expenditure than smear-positive cases.

Although some NTPs retrospectively reimburse diagnostic costs to patients with TB, only $10-20 \%$ of patients receive a TB diagnosis. Patients therefore need to be prepared to meet expenses up front; in practise $80-90 \%$ will not be reimbursed and these fees are likely to be a major deterrent for attending diagnostic services. Furthermore, we have documented elsewhere that patients are often overcharged or pay under-the-counter fees to speed up test results or to be seen earlier than others [20]. These expenses are not documented in their receipts and where 
Table 4 Median costs incurred according to patients' characteristics

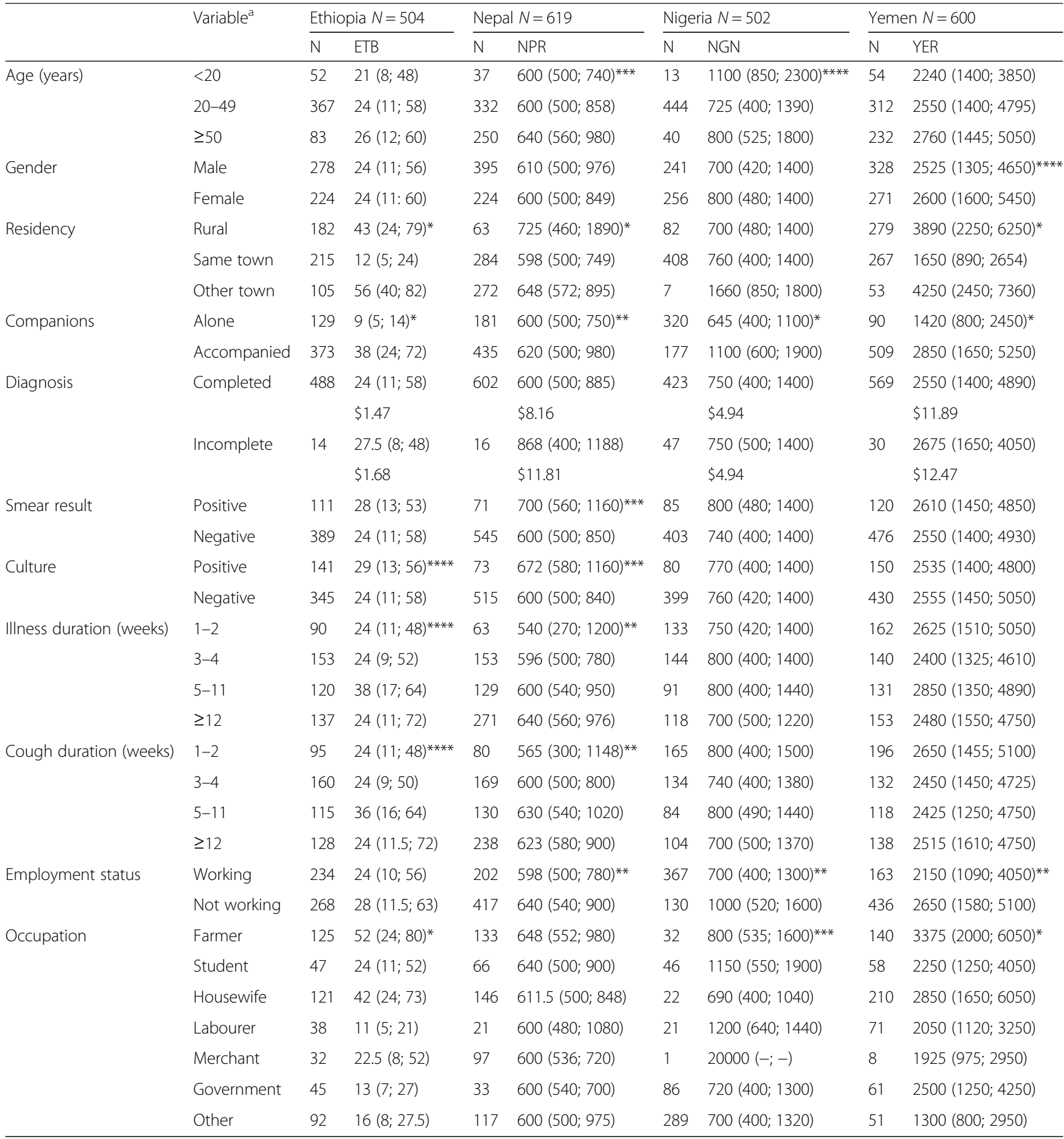

${ }^{a}$ Values are medians and $25-75 \%$ interquartile ranges (IQR) and given in the local currency, unless specified otherwise

${ }^{*} P<0.001,{ }^{* *} P<0.01,{ }^{* * *} P<0.05,{ }^{* * * *} P<0.2$

reimbursement does occur, patients are often only partially reimbursed.

Transport costs also contribute significantly to expenditure in Ethiopia, Nigeria and Yemen, where a high number of patients travel from other towns and rural areas and use buses and taxis. In Ethiopia, the costs reflect the predominantly rural population of the country and the cost of transport from areas with limited road and public transport infrastructure. In Yemen, collective public transport is limited to the main towns and women often rely on private vehicles to attend the fairly centralised diagnostic services. In Nigeria, buses were very limited within the metropolitan areas of the Federal Capital at the time of the study and people relied on 
Table 5 Risk factors for high patient expenditure, odds ratios (OR), adjusted odds ratios (AOR) with 95 \% Confidence intervals (95\% Cl) by country

\begin{tabular}{|c|c|c|c|c|c|c|c|c|}
\hline \multirow[b]{2}{*}{ Variable } & \multicolumn{2}{|l|}{ Ethiopia } & \multicolumn{2}{|l|}{ Nepal } & \multicolumn{2}{|l|}{ Nigeria } & \multicolumn{2}{|l|}{ Yemen } \\
\hline & $\mathrm{OR}$ & $\mathrm{AOR}$ & $\mathrm{OR}$ & $\mathrm{AOR}$ & $\mathrm{OR}$ & AOR & $\mathrm{OR}$ & AOR \\
\hline Age $\geq 50$ & $1.1(0.6-1.8)$ & & $1.3(0.9-1.8)$ & & $1.6(0.8-3.2)$ & & $1.3(0.9-1.9)$ & \\
\hline Male & $0.9(0.6-1.4)$ & & $1.4(0.9-2.1)$ & $2.0(1.3-3.2)$ & $1.1(0.7-1.6)$ & & $0.7(0.5-1.1)$ & \\
\hline Married or with partner & $1.9(1.3-3.0)$ & & $0.8(0.5-1.3)$ & & $1.0(0.7-1.5)$ & & $1.1(0.7-1.7)$ & \\
\hline Rural/other town residency & $23.6(10.2-55)$ & $15.3(6.5-36.0)$ & $1.5(1.0-2.2)$ & & $1.1(0.6-1.8)$ & & $6.9(4.2-11.3)$ & $6.7(4.1-11.0)$ \\
\hline Illiterate & $1.9(1.3-2.9)$ & & $1.7(1.1-2.6)$ & $2.5(1.5-4.0)$ & $2.4(1.4-4.3)$ & $1.9(1.0-3.4)$ & $1.7(1.2-2.5)$ & \\
\hline Education nil or primary & $2.5(1.3-4.8)$ & & $1.4(1.0-2.1)$ & & $1.1(0.7-1.7)$ & & $1.9(1.1-3.3)$ & \\
\hline Accompanied & $19.7(6.1,63)$ & $7.5(2.3-25.2)$ & $1.5(1.0-2.2)$ & & $2.7(1.8-4.2)$ & $2.5(1.6-3.9)$ & $3.4(1.7-7.0)$ & $3.1(1.5-6.5)$ \\
\hline Smear-positive & $0.9(0.5-1.4)$ & & $2.2(1.3-3.7)$ & & $0.8(0.5-1.5)$ & & $1.0(0.6-1.5)$ & \\
\hline Culture-positive & $1.0(0.6-1.6)$ & & $2.2(1.3-3.7)$ & $2.3(1.3-3.8)$ & $1.0(0.6-1.7)$ & & $0.9(0.6-1.4)$ & \\
\hline Illness $\geq 12$ weeks & $1.6(1.0-2.4)$ & & $1.2(0.8-1.7)$ & & $0.9(0.5-1.5)$ & & $0.9(0.6-1.5)$ & \\
\hline Cough $\geq 5$ to 11 weeks & $1.3(0.8-2.0)$ & & $1.3(0.9-2.1)$ & & $1.2(0.7-2.0)$ & & $1.0(0.6-1.6)$ & \\
\hline Not working & $1.2(0.8-1.9)$ & & $1.1(0.8-1.7)$ & & $1.7(1.1-2.7)$ & & $1.4(0.9-2.1)$ & \\
\hline $\begin{array}{l}\text { Farmer, student, } \\
\text { housewife, labourer }\end{array}$ & $3.8(2.2-6.5)$ & & $1.1(0.8-1.6)$ & & $1.4(0.9-2.3)$ & & $2.3(1.3-4.0)$ & \\
\hline
\end{tabular}

share minibuses or taxis to move from the slums surrounding the metropolitan areas. Although transport costs were incurred for different reasons in each location, they represented more than half of patient expenditure to attend diagnostic centres and are thus a major barrier. Addressing these issues would require long term infrastructural development. However interim solutions such as recruiting community volunteers or community workers to organise transport and the provision of support funds that facilitate transport could be explored [21]. Similar issues occur for other diseases such as HIV/AIDS, the management of accidents and emergencies and complicated deliveries.

A high proportion of patients attended with company in all study settings. This was especially prominent in Yemen, where 4 out of 5 patients came accompanied, and significantly increased the costs associated with displacement. In Yemen, gender norms meant that women in particular were required to be accompanied by a male relative and faced particular challenges in accessing a TB diagnosis [20]. The need for company also reflects cultural practices underpinning support to a person perceived to have a mortal illness - in Ethiopia, for example, TB is equated with lung cancer - and the frailty of patients with chronic and debilitating conditions. Rural residents were more likely to attend with company in all countries, which is probably the reason why these patients had higher expenditure in Ethiopia and Yemen than patients from urban areas [11].

Our findings indicate that despite the differences in the settings, patients across LMICs experience many similarities in the type of costs associated with clinic attendance and that it might be feasible to identify patients at risk of high expenditure by conducting a simple questionnaire when they present to diagnostic centres. This is particularly relevant in the context of the Global Plan to Stop TB 2016-2020, which aims to eliminate the number of families facing catastrophic costs due to TB $[1,22]$. In the study context, additional support made available by NTPs could be channelled to those most at risk of high costs, including illiterate patients, those originating from rural areas or attending with company. This approach could also reimburse expenses to all patients investigated for TB; independently of whether the diagnosis is confirmed.

This analysis, however, has several limitations, beginning with the sampling strategy, which carried a risk of selection bias. Participants were recruited using systematic random sampling, rather than randomly, as this suited the objectives of the larger clinical trial [14]. Patients arriving at the beginning of the day might have had different characteristics from those arriving later. We can hypothesise that the former might have resided more locally, or conversely, have travelled the previous day from afar and stayed overnight. Patients arriving early might have been better prepared. Next, second day costs were calculated according to patients' predicted expenses, rather than the actual costs incurred. Moreover, all costs were self-reported, rather than observed by investigators. Actual and predicted expenditure might have been expressed differently by different subgroups of the population and different cultures, as mediated by established social hierarchies, gender roles, economic standing and the distribution of power, to name but a few modifiers. For example, costs which might be overstated by patients in one setting in the hope of financial remuneration might be underreported in another out of individual pride. Women who do not have access to 
household finances might also be unaware of the full cost of attendance. Calculation of costs as a proportion of individual income would have provided a more complete picture of the economic burden for the individual and their family, however including the many variables involved in these calculations was not possible within the confines of a short addition to a large survey and asking participants to disclose their income was considered unreliable.

The costs described here represent only a proportion of the economic barriers faced by individuals with symptoms of $\mathrm{TB}$, as the cost of previous healthcare, visits to the private sector and indirect costs - such as loss of employment and work time - which may constitute a major part of patients' outgoings, were not documented [19, 20, 23-26]. Opportunity costs tend to be higher for people living in poverty, who for the most part work in the informal sector and are vulnerable to loss of income or dismissal from work [27]. In countries with high HIV prevalence, this vulnerability is heightened, as the population perceives that patients with TB are likely to be co-infected with HIV [28]. Furthermore, a large proportion of symptomatic adults do not attend diagnostic centres and these individuals often have fewer financial and social resources at their disposal [20]. Financial barriers could be alleviated at the point of care through further decentralisation of health services [29], the provision of free diagnostic services, transport for remote populations and/or mobilisation of services to remote communities [28, 30, 31].

\section{Conclusion}

The costs incurred by patients are substantial and share common patterns across countries. Removing user fees, transparent charging policies and reimbursing clinic expenses would reduce the poverty-inducing effects of direct diagnostic costs. In locations with limited resources, support could be prioritised for those most at risk of high expenditure; those who are illiterate, attend the service with company and rural residents.

Poverty constitutes a major access barrier for symptomatic adults in low income countries, as recently recognised by the Sustainable Development Goals (SMGs) [32]. Poverty is often compounded by low education and health information, leading to misconceptions of the disease and disempowerment. Rural and urban residence also determines access to diagnostic services. Addressing poverty is likely to be the most crucial factor in determining the success or failure of the Global Health Plan to Stop TB 20162020 as a significant public health problem [1] and recognised as major impediment for the achievement of the TB component of the SMGs [17, 33].

\section{Ethics statement}

The protocol (International Standard Randomized Controlled Trial Number Register ISRCTN53339491) was approved by the WHO Ethics Review Committee, the Liverpool School of Tropical Medicine Ethics Research Committee, and the national and institutional ethics committees of the four countries. Consent and information sheets were translated, and informed witnessed written or oral consent was obtained.

\section{Additional file}

Additional file 1: Multilingual abstracts in the six official working languages of the United Nations. (PDF 314 kb)

\section{Abbreviations}

AOR: adjusted odds rations; Cl: Confidence Intervals; DFiD: Department for International Development; ESRC: Economic and Social Research Council; IQR: interquartile range; NTI: National Tuberculosis Institute; NTPS: national TB programmes; OR: Odds Ratios; SD: standard deviation; TB: tuberculosis;

SDGs: Sustainable Development Goals.

\section{Competing interests}

The authors declare that they have no competing interests.

\section{Authors' contributions}

RMA, MAY, SJT and LEC conceived the study, lead the studies and wrote the study protocol with AR. RMA and LEC conducted data analysis and wrote the initial manuscript. LL, OO, NA-S, NA-A, IA, DG and JBS coordinated the studies in Nigeria, Yemen, Ethiopia and Nepal. EEN conducted laboratory tests for participants in Nigeria. STA and JO and were the State and National TB control programme managers at the time of the study, facilitate the study inception into their control programmes and advised on study design. DG coordinated the studies in Ethiopia. AR and SBS provided advised on TB control policies and how to focus the study within international priorities, supported the development of protocols and commented on earlier drafts of the manuscript. All authors contributed to the final manuscript. All authors read and approved the final manuscript.

\section{Acknowledgements}

This research was funded by the Bill and Melinda Gates Foundation and the United States Agency for International Development through grants awarded to the UNICEF/UNDP/World Bank/WHO Special Programme for Research and Training in Tropical Diseases (Grant Nos. 3636/9900727 and AAGG-00-99-00005-31) and by a joint research programme of the Economic and Social Research Council (ESRC) and the Department for International Development (DfID) (Grant Reference: RES-167-25-0387). The funders had no role in study design, data collection and analysis, decision to publish, or preparation of the manuscript. The authors of this paper alone are responsible for the views expressed in this publication which do not necessarily represent the decisions or policies of the World Health Organization and their institutions. We are also grateful to all laboratory staff and TB control management personnel who supported the enrolment of patients to this and allied studies. Without their help this study would not have been possible.

\section{Author details}

'Liverpool School of Tropical Medicine, Pembroke Place, Liverpool L3 5QA, UK. 'Zankli Medical Center, Abuja, Nigeria. ${ }^{3}$ Bingham University, Nassarawa State, Abuja, Nigeria. ${ }^{4}$ Medical Faculty, Sana'a University, Sana'a, Yemen. ${ }^{5}$ National Tuberculosis Institute, Sana'a, Yemen. ${ }^{6}$ Bushullo Major Health Centre, Awassa, Ethiopia. ${ }^{7}$ Tribhuvan University Institute of Medicine, Kathmandu, Nepal. ${ }^{8}$ Armauer Hansen Research Institute, Addis Ababa, Ethiopia. ${ }^{9}$ The Global Fund to Fight AIDS, Tuberculosis and Malaria, Geneva, Switzerland. ${ }^{10}$ Federal Capital Territory Tuberculosis and Leprosy Control Programme, Abuja, Nigeria. ${ }^{11}$ Nigeria Tuberculosis and Leprosy Control Programme, Abuja, Nigeria. ${ }^{12}$ REACH Ethiopia, Hawassa, Ethiopia. ${ }^{13}$ UNICEF/ UNDP/World Bank/WHO Special Programme for Research and Training in Tropical Diseases, World Health Organization, Geneva, Switzerland. 


\section{References}

1. Uplekar M, Weil D, Lonnroth K, Jaramillo E, Lienhardt C, Dias HM, et al. WHO's new end TB strategy. Lancet. 2015;385(9979):1799-801. doi:10.1016/s0140-6736(15)60570-0.

2. Lonnroth K, Glaziou P, Weil D, Floyd K, Uplekar M, Raviglione M. Beyond UHC: monitoring health and social protection coverage in the context of tuberculosis care and prevention. PLoS Med. 2014;11(9):e1001693. doi:10.1371/journal.pmed.1001693.

3. WHO. Global tuberculosis report 2014. 2014.

4. Kik SV, Denkinger CM, Chedore P, Pai M. Replacing smear microscopy for the diagnosis of tuberculosis: what is the market potential? Eur Respir J. 2014;43(6):1793-6. doi:10.1183/09031936.00217313.

5. Lönnroth K, Jaramillo E, Williams B, Dye C, Raviglione M. Tuberculosis: the role of risk factors and social determinants. In: Blas E, Sivasankara Kurup A, editors. Equity, social determinants and public health programmes. Geneva: World Health Organization; 2010. p. 219-41.

6. Kemp JR, Mann G, Simwaka BN, Salaniponi FML, Squire SB. Can Malawi's poor afford free tuberculosis services? Patient and household costs associated with a tuberculosis diagnosis in Lilongwe. Bulletin of the World Health Organization. 2007;85(8):580-5.

7. Yan F, Thomson R, Tang S, Squire SB, Wang W, Liu X, et al. Multiple perspectives on diagnosis delay for tuberculosis from key stakeholders in poor rural China: Case study in four provinces. Health Policy. 2007:82:186-99.

8. Benatar SR, Upshur R. Tuberculosis and poverty: what could (and should) be done? Int J Tuberc Lung Dis. 2010;14(10):1215-21.

9. Pantoja A, Kik SV, Denkinger CM. Costs of novel tuberculosis diagnosticswill countries be able to afford it? J Infect Dis. 2015;211 Suppl 2:567-77. doi:10.1093/infdis/jiu820

10. Cambanis A, Ramsay A, Yassin MA, Cuevas LE. Duration and associated factors of patient delay during tuberculosis screening in rural Cameroon. Trop Med Int Health. 2007;12(11):1309-14. doi:10.1111/j.1365-3156.2007.01925.x.

11. Ramsay A, Al-Agbhari N, Scherchand J, Al-Sonboli N, Almotawa A, Gammo M, et al. Direct patient costs associated with tuberculosis diagnosis in Yemen and Nepal. Int J Tuberc Lung Dis. 2010;14(2):165-70.

12. Cambanis A, Yassin MA, Ramsay A, Squire SB, Arbide I, Cuevas LE. A one-day method for the diagnosis of pulmonary tuberculosis in rural Ethiopia. Int J Tuberc Lung Dis. 2006;10(2):230-2.

13. Hirao S, Yassin MA, Khamofu HG, Lawson L, Cambanis A, Ramsay A, et al. Same-day smears in the diagnosis of tuberculosis. Trop Med Int Health. 2007:12(12):1459-63. doi:10.1111/j.1365-3156.2007.01952.x

14. Cuevas LE, Yassin MA, Al-Sonboli N, Lawson L, Arbide I, Al-Aghbari N, et al. A multi-country non-inferiority cluster randomized trial of frontloaded smear microscopy for the diagnosis of pulmonary tuberculosis. PLoS Med. 2011;8(7):e1000443. doi:10.1371/journal.pmed.1000443.

15. Cambanis A, Yassin MA, Ramsay A, Bertel Squire S, Arbide I, Cuevas LE. Rural poverty and delayed presentation to tuberculosis services in Ethiopia. Trop Med Int Health. 2005;10(4):330-5. doi:10.1111/j.1365-3156.2005.01393.x.

16. Storla DG, Yimer S, Bjune GA. A systematic review of delay in the diagnosis and treatment of tuberculosis. BMC Public Health. 2008;8:15 doi:10.1186/1471-2458-8-15.

17. Foster $\mathrm{S}$. The economics of tuberculosis diagnosis and treatment. In: Porter J, Grange J, editors. Tuberculosis: an interdisciplinary perspective. London: Imperial College Press; 1999.

18. Lagarde M, Palmer N. The impact of user fees on access to health services in low- and middle-income countries. Cochrane Database Syst Rev. 2011(4):Cd009094. doi:10.1002/14651858.cd009094.

19. Sewell J, Capocci S, Johnson J, Solamalai A, Hopkins S, Cropley I, et al. Expanded blood borne virus testing in a tuberculosis clinic. A cost and yield analysis. J Infect. 2015:70(4):317-23. doi:10.1016/j.jinf.2014.10.014.

20. de Cuevas RM A, Al-Sonboli N, Al-Aghbari N, Yassin MA, Cuevas LE, Theobald SJ. Barriers to completing TB diagnosis in Yemen: services should respond to patients' needs. PLoS One. 2014;9(9):e105194. doi:10.1371/journal.pone.0105194.

21. Li Y, Ehiri J, Hu D, Oren E, Cao J. Framework of behavioral indicators evaluating TB health promotion outcomes: a modified Delphi study of TB policymakers and health workers. Infect Dis Poverty. 2015;4:56. doi:10.1186/s40249-015-0087-4

22. The Global Plan to Stop TB 2016-2020: "Bending the Curve: A global investment framework to win the fight against TB". Stop TB Partnership. http://www.stoptb.org/global/plan/plan2/. Accessed 22 Mar 2016.
23. Tanimura T, Jaramillo E, Weil D, Raviglione M, Lonnroth K. Financial burden for tuberculosis patients in low- and middle-income countries: a systematic review. Eur Respir J. 2014;43(6):1763-75. doi:10.1183/09031936.00193413.

24. Nguyen HT, Hickson Rl, Kompas T, Mercer GN, Lokuge KM. Strengthening tuberculosis control overseas: who benefits? Value Health. 2015;18(2):180-8. doi:10.1016/j.jval.2014.11.008.

25. Oliwa JN, Karumbi JM, Marais BJ, Madhi SA, Graham SM. Tuberculosis as a cause or comorbidity of childhood pneumonia in tuberculosis-endemic areas: a systematic review. Lancet Respir Med. 2015;3(3):235-43. doi:10.1016/\$2213-2600(15)00028-4

26. $\mathrm{Hu} \mathrm{H}$, Chen J, Sato KD, Zhou Y, Jiang H, Wu P, et al. Factors that associated with TB patient admission rate and TB inpatient service cost: a cross-sectional study in China. Infect Dis Poverty. 2016:5(1):4. doi:10.1186/s40249-016-0097-x.

27. Bates I, Fenton C, Gruber J, Lalloo D, Lara AM, Squire SB, et al. Vulnerability to malaria, tuberculosis, and HIV/AIDS infection and disease. Part 1: determinants operating at individual and household level. The Lancet Infectious Diseases. 2004:4:267-77.

28. WHO. Addressing poverty in TB control: options for national TB control programmes. Geneva: World Health Organization; 2005.

29. Tulloch O, Theobald S, Morishita F, Datiko DG, Asnake G, Tesema T, et al. Patient and community experiences of tuberculosis diagnosis and care within a community-based intervention in Ethiopia: a qualitative study. BMC Public Health. 2015;15:187. doi:10.1186/s12889-015-1523-x.

30. Yassin MA, Datiko DG, Tulloch O, Markos P, Aschalew M, Shargie EB, et al. Innovative community-based approaches doubled tuberculosis case notification and improve treatment outcome in Southern Ethiopia. PLoS One. 2013;8(5):e63174. doi:10.1371/journal.pone.0063174.

31. Arinaminpathy N, Dowdy D. Understanding the incremental value of novel diagnostic tests for tuberculosis. Nature. 2015;528(7580):S60-7. doi:10.1038/nature16045.

32. Nations U. Sustainable Development Goals. 2015. https:/sustainabledevelopment un.org/?menu=1300. Accessed 4 Jan 2016.

33. WHO Global Tuberculosis Report 2015. Geneva: WHO; 2015. http://www. who.int/tb/publications/global_report/en/. Accessed 4 Jan 2016.

34. Alkire S, Santos ME. Multidimensional Poverty Index: Oxford Poverty and Human Development Initiative. 2010

\section{Submit your next manuscript to BioMed Central and we will help you at every step:}

- We accept pre-submission inquiries

- Our selector tool helps you to find the most relevant journal

- We provide round the clock customer support

- Convenient online submission

- Thorough peer review

- Inclusion in PubMed and all major indexing services

- Maximum visibility for your research

Submit your manuscript at www.biomedcentral.com/submit 